\title{
Major Genetic Changes in Wheat with Potential to Affect Disease Tolerance
}

\author{
M. J. Foulkes, N. D. Paveley, A. Worland, S. J. Welham, J. Thomas, and J. W. Snape
}

First author: School of Biosciences, University of Nottingham, Sutton Bonington, Loughborough, Leicestershire LS12 5RD, UK; second and fifth authors: ADAS High Mowthorpe, Duggleby, Malton, North Yorkshire, YO17 8BP, UK; third (deceased) and sixth authors: John Innes Centre, Colney, Norwich NR4 7UH, UK; and fourth author: Rothamsted Research, Rothamsted, Harpenden, Hertfordshire AL5 2JQ, UK. Accepted for publication 6 February 2006.

\begin{abstract}
Foulkes, M. J., Paveley, N. D., Worland, A., Welham, S. J., Thomas, J., and Snape, J. W. 2006. Major genetic changes in wheat with potential to affect disease tolerance. Phytopathology 96:680-688.

Selection through plant breeding has resulted in most elite winter wheat germplasm in the United Kingdom containing the Rht-Dlb semidwarfing allele, the 1BL.1RS chromosome arm translocation with rye, and an allele conferring suppression of awns. Near-isogenic lines (NILs) were used to test whether these major genetic changes have had any effect on disease tolerance. The ability of the NILs to tolerate epidemics of Septoria leaf blotch or stripe rust was measured in four field experiments over two seasons. Tolerance was quantified as yield loss per unit of green

1BL.1RS translocation to decrease tolerance; however, this was not consistent across experiments and there was no effect of semi-dwarfing. The awned NIL exhibited decreased tolerance compared with the unawned NIL. There were significant differences in tolerance between the cultivar backgrounds in which the NILs were developed. Tolerance was lower in the modern genetic background of Weston, released in 1996, than in the genetic background of Maris Hunstman, released in 1972. The data suggest that certain physiological traits were associated with the tolerance differences among the backgrounds in these experiments. Potential yield, accumulation of stem soluble carbohydrate reserves, and grain sink capacity were negatively correlated with tolerance, whereas flag leaf area was positively correlated.
\end{abstract} canopy area lost to disease. There was a trend for the presence of the
There have been several major genetic changes in winter wheat (Triticum aestivum L.) grown in the United Kingdom in recent decades; some related to worldwide trends. The presence of awns was selected against (through selection for the awn suppressor at the locus $B 1$ on chromosome 5A) and became rare in commercially popular UK cultivars during the second half of the 20th century (32). The Rht-Dlb (formerly Rht2) semi-dwarfing allele had been introgressed into the majority of cultivars released by the mid-1980s (3) and the 1BL.1RS wheat-rye chromosome arm translocation was present in most feed wheat lines by the mid1990s (9). The translocation, where the wheat 1BS arm is replaced by the homoeologous rye 1RS arm, originally was used to introgress disease resistance genes, which soon were overcome; however, canopy "greening" and yield benefits were conferred which continued to be selected for (10). In addition to these major genetic changes, there also were changes in canopy architecture brought about by phenotypic selection; flag leaves became smaller and culm leaves became more erect (30).

The suppression of awns, Rht-Dlb, and 1BL.1RS commonly are combined in modern high-yielding feed-grade wheat cultivars (30), which tend to demonstrate poor tolerance of Septoria leaf blotch (24). Advances in crop productivity through plant breeding commonly are associated with decreased capacity to tolerate disease (7), although the evidence varies between crop species and specific diseases $(1,22,23,27,28,31,36,38)$. However, correlations between high yield and poor tolerance do not necessarily indicate a causal relationship. Hence, it is worth considering whether there are plausible mechanisms by which specific genetic changes

Corresponding author: M. J. Foulkes

E-mail address: John.Foulkes@ nottingham.ac.uk

DOI: 10.1094/PHYTO-96-0680

(C) 2006 The American Phytopathological Society could have affected the tolerance of modern wheat cultivars. We define tolerance here as the ability to maintain yield performance despite the presence of disease symptoms, rather than, as it is sometimes used, as a synonym for disease resistance.

Long awns have been demonstrated to be a useful selection indicator in wheat for improved production in hot, dry environments (4) where impaired leaf function due to abiotic stress is common. Important diseases, such as Septoria leaf blotch (causal organism; Septoria tritici, anamorph of Mycosphaerella graminicola) commonly cause loss of green laminae area but less commonly affect the awns, so it is possible that awns might also maintain photosynthesis, and hence aid tolerance, when the stress is biotic.

$R h t-D l b$ was almost ubiquitous in the wheat cultivars tested by Parker et al. (24); therefore, any association between $R h t-D l b$ and tolerance could not be observed. The reason for addressing Rht$D 1 b$ in the present study was that semi-dwarfing per se might benefit tolerance, because shorter stems may lead to greater accumulation of water-soluble carbohydrate (WSC) reserves in the stem, because less dry matter is required for structural tissues. In barley, Gaunt and Wright (13) demonstrated that movement of soluble carbohydrate to the grain often was increased in the presence of disease and, hence, might improve tolerance.

1BL.1RS was present in all of the significantly intolerant cultivars tested by Parker et al. (24); however, only in one out of the four which were significantly tolerant. This association is supported by some mechanistic evidence. Shearman et al. (30) reported that the presence of 1BL.1RS apparently increased preanthesis radiation-use efficiency (ratio of aboveground dry matter to radiation interception) and, hence, total aboveground biomass accumulation. Where the predominant effect of disease is to decrease light interception through loss of green area, each unit of disease-induced green area loss might lead to greater yield loss in cultivars with higher radiation-use efficiency. For example, for 
two cultivars contrasting for high and low efficiency incurring equivalent green area loss (and, hence, radiation interception loss) to disease, all things being equal, the high-efficiency cultivar would suffer greater yield loss.

The experiments reported here quantified the disease tolerance of pairs of near-isogenic lines (NILs) which contrasted for +awns versus -awns, Rht-Dlb (semi-dwarf) versus Rht-Dla (tall), or 1BL.1RS versus 1BL.1BS. The background cultivars in which the NILs were developed differed for year of release, canopy architecture, and attainable yield. The objective was to examine whether these major genetic changes are associated with changes in disease tolerance.

\section{MATERIALS AND METHODS}

Experimental sites and plant material. UK weather is very variable; therefore, substantial epidemics of any given disease do not occur every year. To increase the likelihood of obtaining useful data within the period of funding, experiments were conducted at two sites which are prone to different diseases in each of 2 years, 1998-99 and 1999-2000. The diseases used to test tolerance were Septoria leaf blotch at ADAS Rosemaund, Herefordshire and stripe rust (Puccinia striiformis) at ADAS Terrington, Norfolk. NIL backgrounds were selected for each site to ensure susceptibility to the most likely disease (Table 1). There were two adverse consequences of these practical constraints. First, site and pathogen species could not be separated in the analysis. Second, the NILs tested at the two sites differed, because not all the backgrounds of the available NILs were susceptible to both diseases. The work quantified effects of awns in two pairs of NILs contrasting for alleles at $\mathrm{Bl}$ on chromosome $5 \mathrm{~A}$ controlling presence of awns in a Hobbit sib background (unawned Hobbit released 1978) (developed by J. W. Snape). At Rosemaund, two wintertype Hobbit sib NILs were used and, at Terrington, two springtype Hobbit sib NILs were used. Experiments quantified the effects of the Rht-DIb allele in two pairs of NILs of winter wheat, one in Mercia (Rht-Dla, released in 1986) and one in Maris Huntsman (Rht-Dla, released in 1972; developed by A. J. Worland). All NILs were developed following at least six backcrosses to the recurrent parent. The effects of 1BL.1RS were examined using Weston (1BL.1RS) and Chaucer (1BL.1BS), two commercial winter wheat cultivars released by Elsoms Seeds derived from a single $F_{6}$ plant. Hence, the release dates of the backgrounds (taken as the first year on the UK Recommended List or, in the case of Weston and Chaucer, which were not listed, estimated as 1996) varied between 1972 and 1996.

Experiment design and treatments. Sites were selected with at least a 1-year break from cereal crops. Each experiment used a randomized split-plot design with four replicates; subplots were 2 by $18 \mathrm{~m}$. In three experiments, six genotypes were randomized on main plots and two fungicide treatments, nontarget disease control (F1) and full disease control (F2), on subplots. The aim of the F2 treatment (hereafter referred to as "healthy") was to reduce all disease to a nil or low level, whereas the F1 treatment ("diseased") was designed to allow the single target disease to predominate while controlling other diseases to a nil or low levelthus allowing the effects observed to be attributed, as far as possible, exclusively to the target disease. The F1 treatment received quinoxyfen (as commercial product Fortress, Dow) and/or fenpropimorph (Corbel, BASF) at GS31 (33) to control mildew in all experiments, and chlorothalonil (Bravo 500, BASF) or anilazine (Dyrene, Bayer) at GS39 to control $S$. tritici in the stripe rust experiments at Terrington. The F2 treatment received a four-spray program based on the broad-spectrum active ingredients tebuconazole (Folicur, Bayer) and difenoconazole (Plover, Syngenta) tank mixed with disease-specific materials (listed above) as required.

At Rosemaund in 1999, the two fungicide treatments were randomized on main plots and the six genotypes on subplots. Hence, each experiment examined responses of (i) a pair of NILs contrasting for the alleles determining presence $(b 1)$ and absence (BI) of awns, (ii) a pair of NILs contrasting for the $R h t-D l b$ and Rht-Dla alleles, and (iii) Weston (1BL.1RS) and Chaucer (1BL.1BS) (Table 1). At Terrington, spreader plots of cv. Vuka were drilled between each experimental subplot, and plants infected with stripe rust were transplanted into the Vuka plots in March. At ADAS Rosemaund, guard plots of cv. Abbot were sown between each subplot, to reduce drift of fungicide between experimental subplots.

Plot management. Seed was treated with guazatine (300 g a.i. liter $^{-1}$ as the commercial product Panoctine, R.P. Agric), and the experiments were sown in late September or early October. Seed rate was adjusted by genotype according to 1,000 grain weight, to sow 320 seeds $\mathrm{m}^{-2}$. Nitrogen fertilizer was applied as ammonium nitrate in amounts typical of high-input UK wheat-growing systems. Thus, nitrogen inputs varied across the four experiments in the range of 150 to $190 \mathrm{~kg}$ of $\mathrm{N} \mathrm{ha}^{-1}$, and were calculated taking into account the amount of soil mineral $\mathrm{N}$ available in the individual site-seasons. Pesticides and herbicides were used as necessary to minimize the effects of pests and weeds. The plant growth regulator (PGR) chlormequat was applied at GS31 (onset of stem extension) to reduce the risk of lodging and to represent the conventional conditions in which UK winter wheat cultivars have been grown in recent decades (the percentage of UK wheat fields treated with PGRs has increased from $25 \%$ in 1980 to $56 \%$ in 1988 and to $79 \%$ in 1996) (20). There is some evidence that the proportional reduction in plant height in UK conditions with chlormequat may be greater for Rht-Dla (tall) cultivars at $\approx 10 \%$ compared with Rht-Dlb (semi-dwarf) cultivars at $\approx 5 \%$ (11). However, the extent of this differential would be small in absolute terms, in the region of $5 \mathrm{~cm}$. Chlormequat applied at GS31 (as in this study) is not thought to change canopy structure or light attenuation in the post-anthesis period (16), harvest biomass (8), or grain yield in the absence of lodging (15). In the present study, the Rht-Dla NIL was, on average, 14 and $10 \mathrm{~cm}$ taller than the Rht-Dlb NIL in Maris Huntsman and Mercia, respectively. In summary, any differential effect of chlormequat on plant height for the Rht-Dla versus the Rht-Dlb NILs would not be expected to be sufficiently large to affect the identification of genetic differences in physiological traits affecting attainable yield or disease tolerance in the present study.

Crop and disease assessments. Green lamina area indices. Following the method of Parker et al. (24), the effect of foliar disease was quantified as the difference between the healthy and diseased treatments in the areas under the green lamina area index curve in the post-anthesis period (i.e., healthy area duration [HAD] as defined by Waggoner and Berger) (34). Green lamina area index is the planar area of green lamina per unit of ground area (GLAI). At $\approx 10$-day intervals from GS31, percent symptom severity (2) of all foliar diseases and percentage of absolute leaf lamina area that was green were assessed on 10 randomly sampled shoots per subplot, on all leaf layers with green area remaining. Symptoms of stripe rust and Septoria leaf blotch were estimated as the area of lamina containing sporulating structures and associated senescence. At each assessment date, the absolute

TABLE 1. Near-isogenic lines of wheat tested in field experiments at two sites (ADAS Rosemaund, Hereford, UK and ADAS Terrington, Norfolk, UK) in 1999 and 2000

\begin{tabular}{ll}
\hline Rosemaund & \multicolumn{1}{c}{ Terrington } \\
\hline Mercia $R h t-D 1 b$ & Maris Huntsman Rht-Dlb \\
Mercia $R h t-D 1 a$ & Maris Huntsman Rht-Dla \\
Hobbit (spring) awned & Hobbit (winter) awned \\
Hobbit (spring) unawned & Hobbit (winter) unawned \\
Weston (1BL.1RS) & Weston (1BL.1RS) \\
Chaucer (1BL.1BS) & Chaucer (1BL.1BS) \\
\hline
\end{tabular}


lamina areas of the assessed leaves were measured for a subsample of two shoots per subplot by the method of Bryson et al. (6). These measurements, combined with fertile shoot counts, allowed GLAI to be calculated. At every assessment, the crop growth stage was recorded in two replicates.

Shoot number, green area index, and crop dry matter. Growth of the aboveground plant material was analyzed in eight adjacent $0.7-\mathrm{m}$ row lengths per subplot at three stages: GS31, GS61+75 degree-days $\left({ }^{\circ} \mathrm{Cd}\right.$, base temperature $\left.0^{\circ} \mathrm{C}\right)$ and immediately prior to harvest. NILs were sampled on the calendar dates that they reached the relevant stage. In the samplings at GS31 and $\mathrm{GS} 61+75^{\circ} \mathrm{Cd}$, the number of fertile shoots in a $10 \%$ subsample (by fresh weight) was counted, and projected green areas were measured for (i) leaf lamina, (ii) stem and attached leaf sheath, and (iii) ear, using a Delta-T image analysis system (Delta-T Devices; Burwell, Cambridge, UK), and the components summed to give the green area index (the planar area of green canopy area per unit of ground area) (GAI). Aboveground dry matter was measured on a $20 \%$ subsample (by fresh weight) of the sampled material by weighing after drying for $48 \mathrm{~h}$ at $80^{\circ} \mathrm{C}$. At harvest, all plant material was separated into ears and straw. Ears were counted and threshed, and the chaff and the grain, as well as a $25 \%$ subsample of the straw (by fresh weight), were weighed separately after drying for $48 \mathrm{~h}$ at $80^{\circ} \mathrm{C}$.

At GS61 $+75^{\circ} \mathrm{Cd}$, percent WSC content of stems and attached leaf sheaths was assessed in all subplots. Ten fertile shoots were sampled randomly within the subplot and the stems and attached leaf sheaths were dried immediately at $100^{\circ} \mathrm{C}$ for $2 \mathrm{~h}$, as described by Gay et al. (14). Dried samples were used to determine levels of WSC by the anthrone method (37) using fructose as a standard. Stem WSC dry weight was obtained by multiplying the stem-andleaf-sheath dry matter at GS61 $+75^{\circ} \mathrm{Cd}$ by the percent WSC.

Radiation interception and radiation-use efficiency. Interception of photosynthetically active radiation (PAR) (400- to 700-nm wavelength) was measured using a Sunfleck Ceptometer (Delta-T Devices) in all subplots at GS61. Measurements were taken above the crop and at ground level. The PAR extinction coefficient $\left(\mathrm{K}_{\mathrm{PAR}}\right)$ was calculated from GAI and fractional PAR interception (F) at anthesis, using a modified version of an analogy to Beer's Law (equation 1), where Io is the incident PAR and $I$ is the amount of PAR transmitted below a GAI value of L (21):

$$
\mathrm{K}_{\mathrm{PAR}}=-\ln (\mathrm{I} / \mathrm{Io}) / \mathrm{L}
$$

Accumulated PAR interception from GS31 to complete canopy senescence was calculated by applying $\mathrm{K}_{\mathrm{PAR}}$ measured at anthesis to daily values of incident PAR and green area index throughout this period using equation 2 . Healthy $\mathrm{K}_{\mathrm{PAR}}$ differed across site/seasons in the range of 0.48 to 0.74 , with larger values tending to occur at Rosemaund (Table 2). Hence, different $\mathrm{K}_{\mathrm{PAR}}$ values were used for specific genotype-site/season combinations. Healthy $\mathrm{K}_{\mathrm{PAR}}$ values were used in the calculations for both healthy and diseased treatments, because these estimates were considered to most accurately represent interception by green tissues. In the diseased treatment, inaccuracies in the estimation of $\mathrm{K}_{\mathrm{PAR}}$ would occur due to some radiation being intercepted by diseased canopy area.

$$
\mathrm{F}=1-\exp \left(-\mathrm{K}_{\mathrm{PAR}} \times \mathrm{L}\right)
$$

To calculate daily values of GAI, first, green areas of stem and attached leaf sheath, and ear were estimated, assuming values changed linearly with calendar time between relevant samplings at GS31, GS61 $+75^{\circ} \mathrm{Cd}$, and harvest. Second, the green area of lamina was estimated from green lamina area fertile shoot ${ }^{-1}$ assessments at 10-day intervals from GS31 to complete canopy senescence, assuming values changed linearly with calendar time. Green lamina area fertile shoot ${ }^{-1}$ was multiplied by fertile shoots $\mathrm{m}^{-2}$ to obtain GLAI, assuming fertile shoots $\mathrm{m}^{-2}$ changed linearly with time between sequential samplings at GS31, GS61 $+75^{\circ} \mathrm{Cd}$, and harvest. Radiation-use efficiency was measured as the slope of the regression of aboveground dry matter on cumulative PAR interception for the sequential samplings at $\mathrm{GS} 31, \mathrm{GS} 61+75^{\circ} \mathrm{Cd}$, and harvest.

Combine grain yield. In each experiment, combine-harvested grain yields were measured on at least a 2-by-8-m area of each subplot, and values adjusted to $15 \%$ moisture.

Statistical analysis. All statistical analysis was done using GenStat version 7.2 and ASREML version $159 \mathrm{~h}$.

Analysis of variance for crop traits. For individual experiments, analysis of variance (ANOVA) for crop traits fitted the block, mainplot, and subplot structure using random effects, with genotype and fungicide main effects and interactions fitted as fixed effects.

A combined analysis of the full data sets was done using a mixed model with fixed effects for genotype and fungicide main effects and interactions. Random effects were used for withinexperiment blocking factors, for the experiment (site/season) main effects, and interactions of experiment with genotype, fungicide, and genotype-fungicide effects. Separate variances were allowed for blocking structures and residual error within each experiment. In this model, genotype-fungicide effects were effectively assessed with respect to variation between experiments, and a significant difference implied a consistent effect across the four site/seasons that was large with respect to genotype-environment variation. To investigate the structure of the genotype differences, genotype effects were decomposed into the main effects of the four genetic backgrounds (Hobbit, Maris Huntsman, Mercia, and Weston), and the separate effects of the three different NIL contrasts were examined within the relevant genetic background. Specifically, the effect of +awns versus -awns was examined within Hobbit only, the effect of 1BL.1RS versus 1BL.1BS via the difference between Weston and Chaucer, and the effect of Rht$D l b$ versus Rht-Dla across both Maris Huntsman and Mercia. Probability levels quoted in the results refer to these specific tests. Approximate denominator degrees of freedom for $F$ statistics to test fixed effects were generated in ASREML using the method of Kenward and Roger (17).

Regression analysis to estimate disease tolerance. First, the area under the GLAI curve (HAD) (34) was calculated, by the trapezoidal method, across the top five leaves. Disease tolerance then was calculated using a method similar to Parker et al. (24), which fulfils most of the guidelines suggested for identification of tolerance to disease defined by Gaunt (12). An extended regression analysis, pooling data across experiments, was used to detect differences between genotypes in the slope of the fitted straight lines of yield $\left(\mathrm{t} \mathrm{ha}^{-1}\right)$ on HAD. The analysis followed the same principles as the analysis of crop traits across experiments described above, except that differences between fungicide treatments were explained via the impact on HAD rather than by fitting a direct fungicide effect. Fixed effects were used to fit separate intercepts and slopes for the regression of each genotype on HAD and the random model allowed for variation in the intercept and slope of genotype regressions across experiments as well as the withinexperiment blocking structure.

\section{RESULTS}

Disease and green lamina area index. Stripe rust and Septoria leaf blotch were the predominant diseases at the Terrington and Rosemaund sites, respectively, in each year. Other diseases were not present at significant levels. In three experiments, disease pressure reduced GLAI predominantly during the post-anthesis period (Fig. 1). At Terrington in 1999, the onset of effects was earlier, at around flag leaf emergence (GS39). Disease pressure was greatest in 1999 , when GLAI decreased by $\approx 3$ at midgrain filling (GS83); corresponding decreases in 2000 were in the range 1 to 2 . The extent of the decrease in GLAI in the diseased treatment generally was similar for the genotypes.

Rosemaund 1999. Healthy GLAI maxima for genotypes ranged from 6.1 (Chaucer 1BL.1RS) to 7.7 (Hobbit awned). Genotype 
differences generally were not statistically significant until midgrain filling (GS83), when Weston and Chaucer exhibited lower values than Hobbit NILs. Averaging across genotypes, GLAI first was reduced discernibly in the diseased treatment at around flowering (GS61); thereafter effects became progressively larger, with a reduction from 2.6 to 0.1 on 5 July $(P<0.001)$. The genotype-fungicide treatment interaction was statistically significant only on 19 July, with smaller decreases for Weston and Chaucer than other genotypes $(P<0.05)$.

Rosemaund 2000. Healthy GLAI maxima for genotypes ranged from 4.8 (Chaucer) to 7.2 (Mercia $R h t-D 1 b$ ). Averaging across genotypes, GLAI first was reduced in the diseased treatment at around flowering. During grain filling, disease pressure became progressively greater, with a decrease in GLAI from 3.6 to 2.0 by early July $(P<0.001)$. However, the genotypes in the healthy treatment generally responded similarly to the diseased treatment.

Terrington 1999. Healthy genotype maxima ranged from 5.4 (Hobbit awned) to 8.9 (Maris Huntsman Rht-Dlb). The Rht-Dlb NIL showed a trend for greater GLAI compared with the Rht-Dla control as well as other genotypes. Disease pressure was the greatest of any experiment, with GLAI decreased, on average, by 1.0 by flag leaf emergence (GS39), and progressively larger decreases thereafter. The $R h t-D 1 b$ NIL tended to show a larger decrease in the diseased treatment compared with other genotypes during June.

Terrington 2000. Healthy maxima ranged from 4.2 to 5.5. GLAI values were the smallest of the four experiments, and genotype differences were not apparent. Disease pressure was the least of the four experiments. A decrease in the diseased treatment was first detected on 7 June, and there were small decreases thereafter of $\approx 1$ GLAI unit. The extent of the small reduction in GLAI was similar for all genotypes.

Flowering dates were similar for the genotypes; on average, ranging from 9 to 11 June. Therefore, these had little effect on the relative disease and green area values observed on a given date. The two pairs of Hobbit NILs were in spring ( $V r n)$ and winter (vrn) backgrounds. However, from early October sowings in England, differences in flowering date due to Vrn versus vrn typically are only small. When sown at this time, the vernalization requirement of vrn lines normally is satisfied (preventing delayed flowering), whereas there is insufficient thermal time for Vrn lines to reach terminal spikelet prior to colder winter temperatures slowing spikelet primordia production (thus avoiding advanced flowering). Therefore, the spring Hobbit NILs at Terrington flowered within 1 or 2 days of the winter genotypes and were similar in their relative flowering dates to the winter Hobbit NILs lines at Rosemaund (Fig. 1A and B; GS61 = flowering date). Hence, the

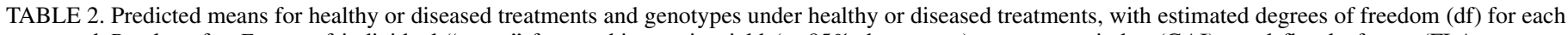

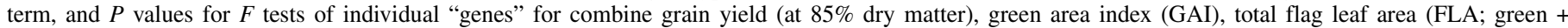

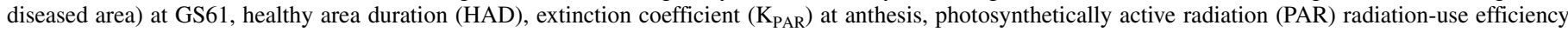
(RUE) from GS31 to complete canopy senescence, stem water-soluble carbohydrate (WSC) at GS61+75 $\mathrm{Cd}$, and number of grains per square meter

\begin{tabular}{|c|c|c|c|c|c|c|c|c|}
\hline \multirow[b]{2}{*}{ Factor combination $^{a}$} & \multicolumn{8}{|c|}{ Response variable } \\
\hline & Grain yield t ha ${ }^{-1}$ & GAI & $\mathrm{FLA} \mathrm{cm}^{2 \mathrm{~b}}$ & HAD & $\mathrm{K}_{\mathrm{PAR}}$ & $\mathrm{RUE}_{\text {PAR }} \mathrm{g} \mathrm{MJ}^{-1}$ & Stem WSC t ha ${ }^{-1}$ & Grains $\mathrm{m}^{-2} \times 10^{-3}$ \\
\hline Diseased & 4.97 & 3.96 & 34.8 & 60.4 & 0.71 & 2.40 & 1.87 & 15.2 \\
\hline Healthy & 6.93 & 5.23 & 34.8 & 120.7 & 0.57 & 2.54 & 2.11 & 16.4 \\
\hline Average SED ${ }^{\mathrm{e}}$ & 0.49 & 0.24 & 0.70 & 11.7 & 0.03 & 0.18 & 0.12 & 0.8 \\
\hline \multicolumn{9}{|l|}{ Diseased } \\
\hline Mercia $R h t-D 1 b$ & 5.20 & 4.58 & 27.8 & 77.5 & 0.63 & 2.12 & 1.71 & 16.2 \\
\hline Mercia Rht-Dla & 5.32 & 3.64 & 32.3 & 69.9 & 0.74 & 2.85 & 1.64 & 17.2 \\
\hline M. Hunt. Rht-D1b & 4.04 & 4.04 & 42.1 & 48.3 & 0.70 & 2.08 & 1.57 & 13.9 \\
\hline M. Hunt. Rht-Dla & 4.60 & 3.70 & 41.7 & 42.4 & 0.90 & 2.55 & 1.61 & 9.8 \\
\hline Hobbit awned & 4.80 & 3.94 & 35.6 & 60.6 & 0.70 & 2.27 & 1.94 & 14.7 \\
\hline Hobbit unawned & 5.08 & 3.31 & 37.1 & 64.1 & 0.80 & 2.21 & 1.99 & 14.3 \\
\hline Weston 1BL.1RS & 5.47 & 4.14 & 29.6 & 60.8 & 0.58 & 2.60 & 2.42 & 17.8 \\
\hline Chaucer 1BL.1BS & 5.26 & 4.32 & 32.5 & 59.3 & 0.58 & 2.54 & 2.09 & 17.4 \\
\hline \multicolumn{9}{|l|}{ Healthy } \\
\hline Mercia $R h t-D 1 b$ & 6.49 & 5.62 & 27.4 & 129.2 & 0.51 & 2.57 & 2.06 & 18.2 \\
\hline Mercia Rht-Dla & 6.60 & 5.14 & 32.1 & 136.0 & 0.56 & 2.66 & 1.91 & 18.2 \\
\hline M. Hunt. Rht-D1b & 6.49 & 5.68 & 42.7 & 118.9 & 0.56 & 2.40 & 1.84 & 14.2 \\
\hline M. Hunt. Rht-D1a & 6.62 & 5.72 & 40.9 & 112.1 & 0.61 & 2.48 & 1.71 & 11.7 \\
\hline Hobbit awned & 7.04 & 4.78 & 35.5 & 118.9 & 0.61 & 2.36 & 2.18 & 15.4 \\
\hline Hobbit unawned & 6.45 & 4.89 & 39.0 & 114.6 & 0.61 & 2.41 & 2.06 & 16.1 \\
\hline Weston 1BL.1RS & 8.04 & 5.16 & 27.4 & 123.3 & 0.52 & 2.60 & 2.63 & 18.8 \\
\hline Chaucer 1BL.1BS & 7.69 & 4.86 & 33.3 & 112.7 & 0.57 & 2.84 & 2.49 & 18.8 \\
\hline Average SED & 0.52 & 0.55 & 3.0 & 12.9 & 0.09 & 0.29 & 0.26 & 1.6 \\
\hline \multicolumn{9}{|l|}{ Estimated $\mathrm{df}^{\mathrm{c}}$} \\
\hline Fung & $5.1 * *$ & $1.6 *$ & 63.0 & $3.0 *$ & 2.1 & 2.8 & 4.3 & 3.3 \\
\hline $\mathrm{BG}$ & $13.6^{* *}$ & 8.6 & $60.8 * * *$ & 12.9 & 10.8 & 11.2 & $10.6^{*}$ & $13.6^{* * *}$ \\
\hline $\mathrm{BG} \times$ fung & $9.6 * *$ & 7.1 & 54.9 & 11.9 & $51.5^{*}$ & 10.4 & 64.4 & 12.2 \\
\hline \multicolumn{9}{|l|}{$P$ value for $F$ statistics } \\
\hline Fung & 0.008 & 0.104 & 0.633 & 0.014 & 0.055 & 0.495 & 0.415 & 0.199 \\
\hline Background & $<0.001$ & 0.250 & $<0.001$ & 0.042 & 0.086 & 0.088 & 0.001 & $<0.001$ \\
\hline Awns & 0.556 & 0.528 & 0.127 & 0.944 & 0.483 & 0.980 & 0.863 & 0.917 \\
\hline Rht & 0.399 & 0.365 & 0.143 & 0.557 & 0.176 & 0.065 & 0.602 & 0.216 \\
\hline 1BL.1RS & 0.305 & 0.935 & 0.023 & 0.324 & 0.806 & 0.588 & 0.194 & 0.812 \\
\hline Fung $\times$ BG & 0.003 & 0.112 & 0.873 & 0.355 & 0.024 & 0.998 & 0.577 & 0.989 \\
\hline Fung $\times$ awns & 0.009 & 0.172 & 0.493 & 0.473 & 0.092 & 0.670 & 0.330 & 0.404 \\
\hline Fung $\times$ Rht & 0.470 & 0.395 & 0.899 & 0.577 & 0.108 & 0.059 & 0.619 & 0.765 \\
\hline Fung $\times 1$ BL1RS & 0.622 & 0.470 & 0.291 & 0.378 & 0.601 & 0.234 & 0.267 & 0.767 \\
\hline
\end{tabular}

a Background denotes the four genetic backgrounds (Hobbit, Maris Huntsman, Mercia, and Weston); BG denotes the eight background-gene combinations.

${ }^{\mathrm{b}}$ FLA was taken according to assessment date nearest to GS61.

c Estimated df $*=P<0.05, * *=P<0.01$, and $* * *=P<0.001$.

${ }^{\mathrm{d}} P$ value for $F$ statistics (data not shown), based on estimated df.

e $\mathrm{SED}=$ standard error of the difference of the means. 
potential confounding effect of development due to Vrn or vrn was not a factor in the study.

HAD. Disease was quantified through disease-induced loss of GLAI, because this provides a measurement of the effects of disease that accounts for differences in canopy size across sites and seasons and relates most directly to resource capture. Although there were few differences in GLAI through the postanthesis period among the genotypes, HAD differed between the four genetic backgrounds (Table $2 ; P<0.05$ ), with Mercia having a high HAD value and Maris Huntsman a low value. On average, HAD was decreased in the diseased treatment by $\approx 50 \%$, and there was no significant genotype-fungicide interaction.

Combine grain yield. Among the genotypes, the expected yield progress with breeding was observed $(P<0.001)$ (Table 2$)$ : Weston and Chaucer (released 1996) $>$ Mercia Rht-Dla (released 1986) > Hobbit unawned (released 1978) or Maris Huntsman RhtDla (released 1972). Averaging across site/seasons and genotypes, disease decreased grain yield by $1.96 \mathrm{t} \mathrm{ha}^{-1}$. Averaging across sites, yield losses were greater in 1999 at $\approx 3 \mathrm{t} \mathrm{ha}^{-1}$ than in 2000 at $\approx 1.5 \mathrm{t} \mathrm{ha}^{-1}$, following the pattern of disease-induced GLAI loss. There was a genetic background-fungicide interaction $(P<0.01)$ where the higher yielding Weston generally showed greater yield losses than Hobbit, Mercia, or Maris Huntsman. There was also $\mathrm{a}+$ or -awns-fungicide interaction $(P<0.01)$, with the Hobbit awned NIL losing more yield than the unawned NIL in the diseased treatment. There was no consistent effect of $R h t-D 1 b$ on yield, but there was a trend for an increase in yield with 1BL.1RS $(P=0.08)$.

Relationship between combine grain yield and HAD: disease tolerance. Disease tolerance was estimated as the slope of the linear relationship of grain yield on HAD across treatments of contrasting disease (Fig. 2; Table 3). Shallow slopes indicate tolerance and steep slopes, intolerance.

Effect of pathogen type on tolerance. The results can be used to a limited extent to consider the relative tolerances of Septoria leaf blotch and stripe rust, because it is possible to break the "experiment" term into its site or pathogen type and season components, noting that site and pathogen type cannot be separated in these experiments. Table 4 shows the deviations from the mean slope of grain yield on HAD (disease tolerance) for the site or pathogen type and season combinations. There was no consistent pattern to suggest that the tolerances differed between site or pathogen types, although the tolerances tended to be greater at the Septoria leaf blotch site than at the stripe rust site. The overriding effect was the greater tolerance at the Rosemaund site in 2000. This occurred in all of the three loci contrasts but was most noticeable in the minus 1BL.1RS NIL (data not shown). Therefore, the results suggested that tolerances of Septoria leaf blotch and stripe rust were not greatly different in these experiments. However, the possibility remains that some unknown site effect may have counteracted an underlying pathogen-type effect.

Effect of wheat genotype on tolerance. The presence of awns decreased tolerance $\left(0.036\right.$ versus $\left.0.029 \mathrm{t} \mathrm{ha}^{-1} \mathrm{HAD}^{-1}\right)$ in the Hobbit NILs $(P<0.05)$. Neither the Rht-Dlb allele (in Mercia or Maris Huntsman NILs) nor the 1BL.1RS translocation (Weston 1BL.1RS versus Chaucer 1BL.1BS) had a significant effect on tolerance. There were, however, differences between the genetic backgrounds $(P<0.05)$, with the modern background Weston $\left(0.034 \mathrm{t} \mathrm{ha}^{-1} \mathrm{HAD}^{-1}\right)$ exhibiting decreased tolerance compared with Maris Huntsman $\left(0.026 \mathrm{t} \mathrm{ha}^{-1} \mathrm{HAD}^{-1}\right)$.
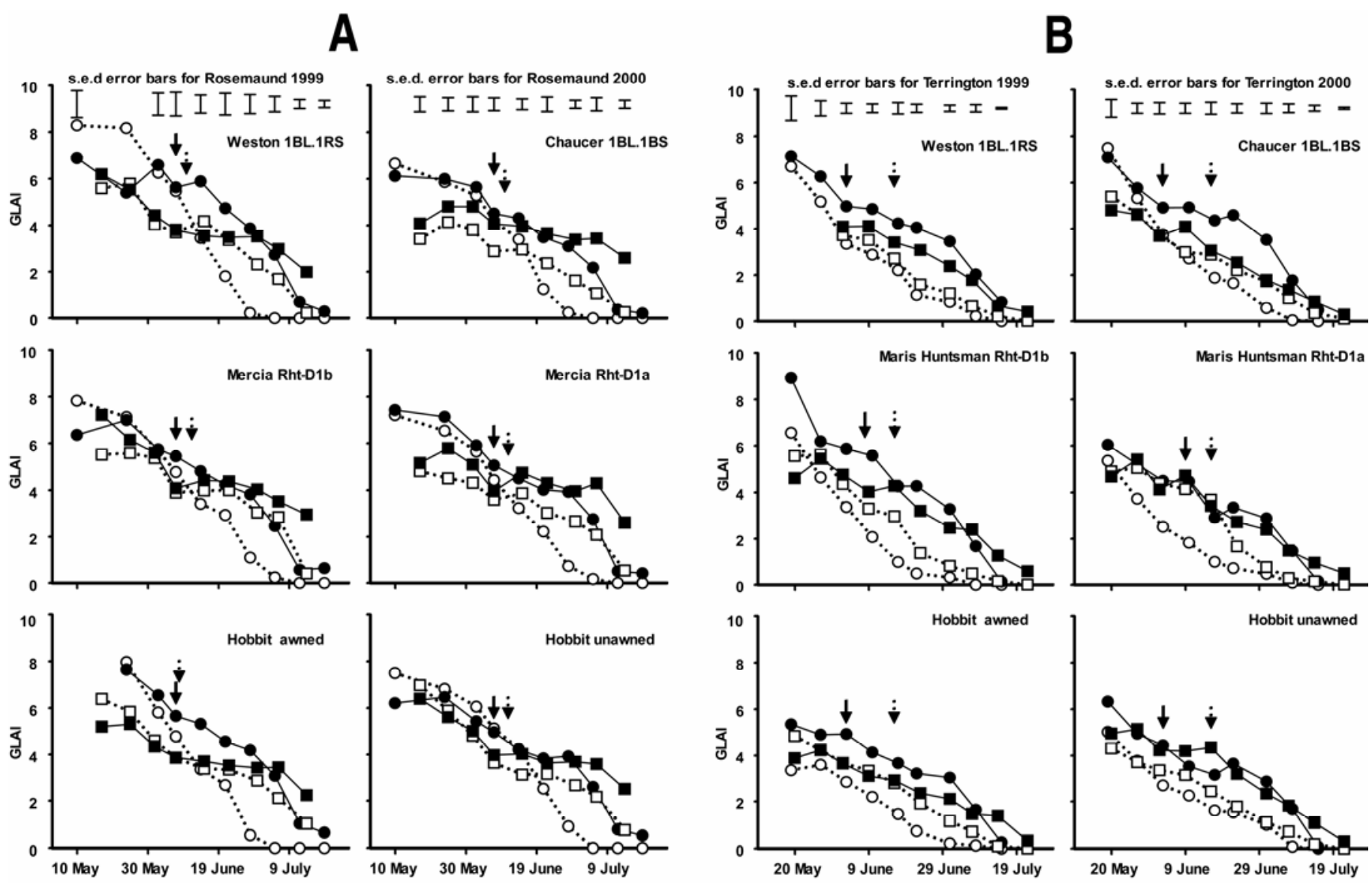

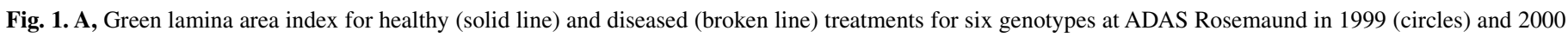

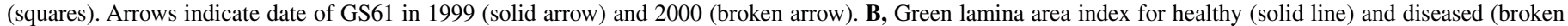

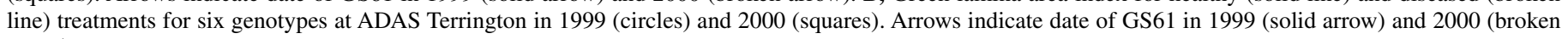
arrow). 
The intercept values were estimated at $\mathrm{HAD}=150$, in order to provide an estimate of attainable yield within the $x$-axis range of the data (Table 3). As expected, the intercept values were highly correlated with, but somewhat higher than, the mean grain yield values from the healthy plots (Table 2).

Crop physiological traits. Several physiological traits may have caused the differences in tolerance observed between the genetic backgrounds: namely, maximum canopy green area, extinction coefficient, the amount of stem soluble carbohydrate accumulated, radiation-use efficiency, and grain number per unit area (grain sink strength).

Green area index and flag leaf area. Green area index reaches its maximum once the ears are fully emerged; therefore, the GS61
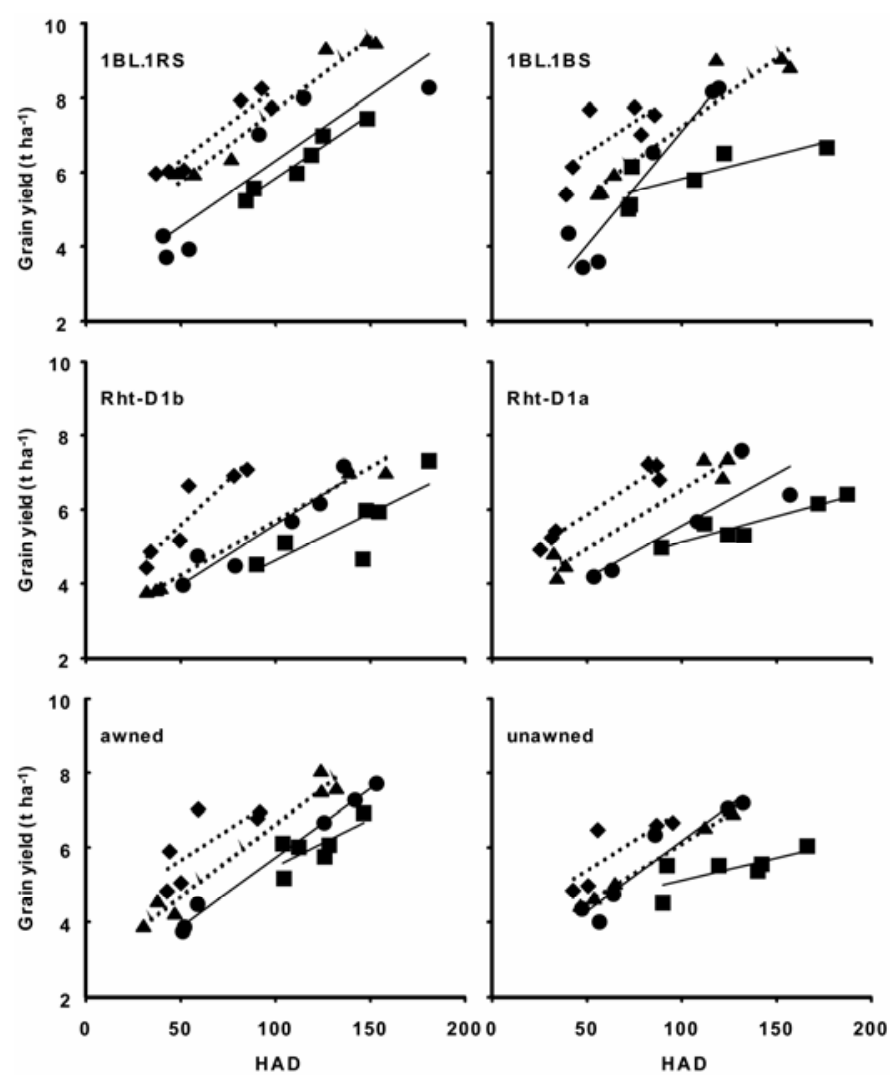

Fig. 2. Area under green lamina area index curve post anthesis (healthy area duration [HAD]) against combine grain yield ( $\mathrm{t} \mathrm{ha}^{-1} 85 \%$ dry matter) at ADAS Rosemaund in 1999 (circles) and 2000 (squares) and ADAS Terrington in 1999 (triangles) and 2000 (diamonds). measurements were close to the peak GAI. Although total GAI was similar among genotypes, the distribution of green area between leaf layers differed. Flag leaf area varied between backgrounds in the range of 27 to $43 \mathrm{~cm}^{2}$, with Weston showing smaller values than other backgrounds $(P<0.001)$ (Table 2$)$. There was one significant difference $(P<0.05)$ in flag leaf area within pairwise NIL contrasts, with Chaucer (1BL.1BS) and Weston (1BL.1RS) having values of 33.3 and $27.4 \mathrm{~cm}^{2}$, respectively. Differences in areas of leaves II and III were not significant. Green stem and ear area indices did not differ significantly among the genotypes. Disease, on average, decreased GAI by $1.27(P<0.05)$, but genotypes responded similarly. This is consistent with similar GLAI and HAD responses of genotypes to the fungicide.

$K_{P A R}$ at GS61. Averaging across site or seasons, healthy genotypes differed in $\mathrm{K}_{\mathrm{PAR}}$ in the range of 0.52 to 0.61 (Table 2). Within pairwise contrasts, differences were small and nonsignificant. There was a trend for differences across the genetic backgrounds $(P=0.086)$. Weston showed smaller $\mathrm{K}_{\mathrm{PAR}}$ compared with Hobbit, with intermediate values for Mercia and Maris Huntsman. Disease increased $\mathrm{K}_{\mathrm{PAR}}$ from 0.57 to $0.71(P=0.055)$ on average. This apparent increase probably was caused by greater interception by nongreen (i.e., diseased) tissues rather than an "intrinsic" increase in extinction coefficient of green tissues. There was a genetic background-fungicide interaction $(P<0.05)$ because disease increased $K_{\mathrm{PAR}}$ for Hobbit and Maris Huntsman more than for Mercia and Weston.

Radiation-use efficiency. Averaging over site/seasons, healthy radiation-use efficiency differed among genotypes in the range of 2.36 to $2.84 \mathrm{~g} \mathrm{MJ}^{-1}$ (Table 2). There was a trend for a reduction in radiation-use efficiency with the Rht-Dlb allele $(P=0.060)$. Within the awned versus unawned and 1BL.1RS versus 1BL.1BS contrasts, differences were small and not statistically significant. Comparing across genetic backgrounds, there was some indication that Weston had greater radiation-use efficiency than Hobbit $(P=0.088)$. Disease reduced efficiency by $0.14 \mathrm{~g} \mathrm{MJ}^{-1}$ on average, although this reduction was not statistically significant.

TABLE 4. Deviations from the disease intolerance ( $\mathrm{t} \mathrm{ha} \mathrm{h}^{-1}$ per healthy area duration [= green area duration]) averaged across the four experiments, for the individual experiments representing site/pathogen and season combinations ${ }^{\mathrm{a}}$

\begin{tabular}{lcc}
\hline & \multicolumn{2}{c}{ Site/pathogen type } \\
\cline { 2 - 3 } Year & Rosemaund/Septoria & Terrington/Stripe rust \\
\hline 1999 & 0.0032 & 0.0042 \\
2000 & -0.0133 & 0.0059 \\
\hline
\end{tabular}

a Standard error $=0.0052$.

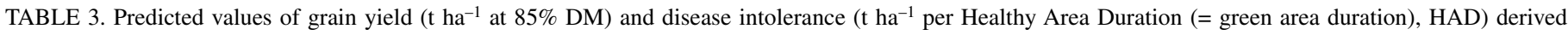

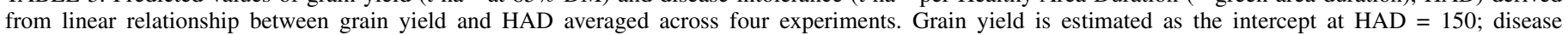
intolerance is estimated as the slope of the linear relationship between grain yield and HAD (higher values relate to greater intolerance)

\begin{tabular}{|c|c|c|c|c|}
\hline \multirow[b]{2}{*}{ Genotype } & \multicolumn{2}{|c|}{ Grain yield } & \multicolumn{2}{|c|}{ Disease intolerance } \\
\hline & $\mathrm{t} \mathrm{ha}^{-1}$ & $\operatorname{SED}(\mathrm{df}=34)^{\mathrm{a}}$ & $\mathrm{t} \mathrm{ha}^{-1}$ per HAD & $\operatorname{SED}(\mathrm{df}=27)^{\mathrm{a}}$ \\
\hline Mercia Rht-Dlb & 7.57 & $\ldots$ & 0.033 & $\ldots$ \\
\hline Mercia Rht-Dla & 7.47 & 0.243 & 0.027 & 0.0057 \\
\hline M. Huntsman Rht-D1b & 6.87 & $\ldots$ & 0.025 & $\ldots$ \\
\hline M. Huntsman Rht-Dla & 7.70 & 0.362 & 0.028 & 0.0040 \\
\hline Hobbit awned & 8.22 & $\ldots$ & 0.036 & $\ldots$ \\
\hline Hobbit unawned & 7.43 & 0.239 & 0.029 & 0.0036 \\
\hline Weston 1BL.1RS & 8.94 & $\ldots$ & 0.036 & $\ldots$ \\
\hline Chaucer 1BL.1BS & 8.52 & 0.235 & 0.031 & 0.0034 \\
\hline SED average ${ }^{b}$ & 0.286 & $\ldots$ & 0.0044 & $\ldots$ \\
\hline Maximum & 0.373 & $\ldots$ & 0.0057 & $\ldots$ \\
\hline Minimum & 0.233 & $\ldots$ & 0.0034 & $\ldots$ \\
\hline
\end{tabular}

a SED (standard error of the difference of the means) for comparing lines within a pair of near-isogenic lines.

b SED for comparing lines between pairs of near-isogenic lines. 
Stem soluble carbohydrate reserves. Healthy genotypes differed in the amount of stem soluble carbohydrate accumulated from 171 to $263 \mathrm{~g} \mathrm{~m}^{-2}(P<0.001)$ (Table 2). Within the pairwise contrasts, the effects of the awns, the Rht-Dlb allele, and the 1BL.1RS translocation were neutral on stem WSC accumulation. However, there was an effect of genetic background, with Weston exhibiting greater accumulation of stem carbohydrate than other genetic backgrounds $(P<0.05)$. The small reduction in stem WSC due to disease, $24 \mathrm{~g} \mathrm{~m}^{-2}$ on average, was not statistically significant.

Grains $m^{-2}$. The effects of the pairwise contrasts between NILs were not statistically significant. Differences were observed between genetic backgrounds in the healthy treatment, ranging from 13,000 (Maris Huntsman) to 18,800 (Weston) grains $\mathrm{m}^{-2}(P<$ 0.001 ) (Table 2). This reflected the expected increase in grain numbers underlying recent genetic progress in yield potential in the United Kingdom (24). Overall, the reduction in the diseased treatment of 1,200 grains $\mathrm{m}^{-2}$ was not statistically significant.

Correlations between traits and tolerance. Of the traits exhibiting significant variation between genetic backgrounds, grain yield, stem WSC, and grains $\mathrm{m}^{-2}$ were negatively correlated with tolerance ( $r=-0.63,-0.73$, and -0.43 , respectively), and flag leaf area was positively correlated with tolerance $(r=0.67)$.

\section{DISCUSSION}

The two pathogens against which tolerance was quantified differ in their mode of pathogenicity; $S$. tritici is a necrotroph whereas $P$. striiformis is an obligate biotroph. Therefore, a difference in tolerance might have been anticipated. There was no evidence that site or pathogen type affected tolerance to a different extent than season, although the number of comparisons available was small. Hence, the inconsistent trend for greater yield loss per unit of green area lost to stripe rust compared with Septoria leaf blotchwhich agrees with earlier data (25) - might equally be due to environmental differences between the sites. Potential differences between the effects of pathogen types will not be properly quantified until they are compared directly on common host genotypes under common environments; this may be difficult to achieve in field experiments.

The differences in tolerance detected between genetic backgrounds exceeded those within the pairwise NIL contrasts. This suggests that traits other than those related to awns, semi-dwarfing, or 1BL.1RS were responsible for most of the observed differences among the wheat genotypes examined. The discussion will briefly review the findings on each of the pairwise NIL contrasts, before considering what those other traits might be.

The awned NIL exhibited greater disease susceptibility, significantly increased attainable yield, and decreased tolerance compared with the unawned NIL. It is conceivable that these differences were due to the presence of awns. In spring wheat in the Great Plains, $\mathrm{F}_{3}$-derived sib lines grown in the absence of significant abiotic stress mostly showed no differences in grain yield between awned and unawned sibs; however, where differences did occur, awned sibs were higher yielding (35). However, there are no reports of an increase in attainable yield with awns under UK conditions in the absence of substantial abiotic stress, and data from a doubled-haploid mapping population derived from Beaver (unawned) $\times$ Soissons (awned) have shown no consistent effect of awns on grain yield (M. J. Foulkes, J. W. Snape, and R. SylvesterBradley, unpublished data). Hence, it is possible that the Hobbit NILs were not completely isogenic and an allele deleterious to yield is tightly linked to the awn suppression allele on chromosome 5A. In this instance, the awn allele is derived from a wild source, an accession of Triticum spelta, and might have linkage drag for a yield increasing allele (32).

Semi-dwarfing due to Rht-Dlb did not result in an increase of either stem WSC reserves or tolerance. The increase in the per- centage of the stem dry matter partitioned as soluble carbohydrate in the semi-dwarf NILs was counteracted by a proportional reduction in total stem dry matter. These findings agree with those reported by Foulkes et al. (9) for effects of the Rht-Dlb allele on stem carbohydrate in Rht NILs in UK winter wheat backgrounds, and with the absence of reports of increased stem-soluble carbohydrate with $R h t-D 1 b$ from other parts of the world. One piece of work in Australia reported a decrease in stem WSC with the Rht$D 1 b$ allele in spring wheat isogenics (5).

There were marginal trends for increased attainable yield and decreased tolerance with 1BL.1RS, although these effects were not statistically significant. There was evidence of a decrease in flag leaf size with 1BL.1RS. The implications of this for tolerance will be covered later.

The genetic backgrounds in which the NILs were developed showed substantial phenotypic differences and can be considered as being broadly representative of the types of cultivars grown during the periods in which they were in commercial use. The most modern background, Weston, had significantly higher stem soluble carbohydrate dry matter $(P<0.001)$, radiation-use efficiency $(P=0.09)$, and grains $\mathrm{m}^{-2}(P<0.001)$ than the oldest background, Maris Hunstman. No differences were found in GAI; however, more modern backgrounds had a smaller proportion of their total GAI in the flag leaves. Drawing conclusions on breeding changes based on changes in only four genetic backgrounds is not possible with confidence. However, it is interesting to note that these findings are all in agreement with those of Shearman et al. (30), who studied a set of eight historic UK wheat cultivars released from 1972 to 1996 . Of the phenotypic differences reported here, grain yield, soluble carbohydrates, and grains $\mathrm{m}^{-2}$ were negatively correlated with tolerance, and flag leaf area was positively associated. Such correlations do not necessarily imply a causal link; therefore, we consider below whether there are plausible mechanistic explanations for the effects observed.

If there is insufficient positive selection for tolerance in plant breeding, our results suggest that it is likely that increases in attainable yield may lead to decreased tolerance. Healthy crops of modern cultivars produce higher yields for a given green area duration, apparently due to increased radiation-use efficiency (30). Therefore, yield loss per unit loss of green area duration due to disease may be greater in more modern cultivars, because they apparently convert radiation into grain dry matter more efficiently. Where breeding lines are selected for yield in the absence of fungicide treatment (for example, when breeding for low potential yield environments or resource-poor farming systems), the process includes selection for disease resistance and tolerance. However, in northwestern Europe, cultivars are selected predominantly for fungicide-treated yield. Although disease resistance is selected for visually in early generations in untreated ear-rows or small plots, which usually are not taken to yield, there is no effective selection for tolerance at any stage. This may explain why cultivars with sufficient resistance to express only slight symptoms under most conditions are relatively intolerant of foliar diseases and typically yield $\approx 1.5$ tonnes per hectare less in the absence of fungicide treatment.

The least tolerant genetic background (Weston) had the highest accumulation of stem soluble carbohydrate in the present study. The study of Shearman et al. (30) showed that increases in stem carbohydrate with breeding were positively correlated with yield potential, and concluded that a high proportion of the soluble stem reserve is utilized even under favorable post-anthesis conditions in modern UK cultivars. Therefore, when the post-anthesis duration of the canopy (and hence photosynthesis) is constrained by disease, there may be little scope for further increasing soluble carbohydrate utilization. Hence, unlike in barley (13), accumulation and utilization of stem carbohydrate (and hence the benefit to yield) appear similar in the presence or absence of disease. This agrees with the data of Parker et al. (24), who found no 
relationship between stem reserves and tolerance. Hence, the evidence available to date suggests that greater stem reserves, being equally beneficial to yield in both the presence and absence of disease, might be discounted as being beneficial to tolerance (as defined here by the slope of the disease-yield loss relationship) in currently commercial UK winter wheat cultivars. The negative association with tolerance may be due to auto correlation, because increases in stem soluble carbohydrate may occur in parallel with other phenotypic changes which are deleterious to tolerance.

Provided there is no counteracting change in potential grain size, higher grains $\mathrm{m}^{-2}$ represents an increase in grain sink capacity for assimilate. Previous work has found a positive linear increase in grains $\mathrm{m}^{-2}$ in recent decades with UK breeding (30), but no change in potential grain weight or final grain dry weight (29). Similar trends with year of release were observed in the four genetic backgrounds in the present investigation. All else being equal, a more sink-limited cultivar could lose more source to disease before source became limiting, leading to a shallower disease-yield loss relationship (greater disease tolerance). This might partly explain the tendency for lower tolerances in the more modern backgrounds in the present study. However, caution is required in interpreting the results, because (i) trends with respect to year of release were observed across only four backgrounds and cannot be certain and (ii) it was not possible to quantify the source/sink balance of the genetic backgrounds from the measurements taken-partly because source and sink interact (for example, shortage of sink capacity can have a negative feedback effect on radiation-use efficiency).

There was no increase in radiation-use efficiency in the diseased treatment. This contrasts with data from spring wheat in Israel suggesting that tolerance of the cv. Miriam to $S$. tritici was attributed to a higher rate of carbon fixation per unit of residual green leaf area of diseased plants than in healthy plants (39). This remains one of the few cases of a mechanism for tolerance being reported and it is not known whether such a response might explain some of the tolerance reported for other wheat cultivars $(19,26,38)$.

For simplicity, our analysis of resource capture considered the upper canopy as one functional unit, intercepting PAR. In reality, the upper canopy is composed of layers of culm leaves. The uppermost layer (the flag leaves) tends to be least diseased, because it is the latest to emerge and furthest removed vertically from infectious lesions on leaf layers below (18). Hence, for a given amount of symptom area or disease-induced green area loss in the upper canopy as a whole, cultivars with large flag leaves are likely to suffer less yield loss. It is possible that part of the reported association (24) between presence of 1BL.1RS and poor tolerance may be due, at least in part, to reduced flag leaf size.

\section{ACKNOWLEDGMENTS}

Funding from Defra and the Home-Grown Cereals Authority is gratefully acknowledged. We thank many colleagues in ADAS for conducting the field experiments.

\section{LITERATURE CITED}

1. Andenow, Y. M., Hulluka, M., Belay, G., and Tesemma, T. 1997. Resistance and tolerance to leaf rust in Ethiopian tetraploid wheat landraces. Plant Breed. 116:533-536.

2. Anonymous. 1972. Guide for Assessment of Cereal Diseases. Ministry of Agriculture Fisheries and Food, Plant Pathology Laboratory, Harpenden, UK.

3. Austin, R. B., Ford, M. A., and Morgan, C. L. 1989. Genetic improvement in the yield of winter: A further evaluation. J. Agric. Sci. 112:295-301.

4. Blum, A. 1986. The effect of heat stress on wheat leaf and ear photosynthesis. J. Exp. Bot. 37:111-118.

5. Borrell, A. K., Incoll, L. D., and Dalling, M. J. 1993. The influence of the $R h t 1$ and $R h t 2$ alleles on the deposition and use of stem reserves in wheat. Ann. Bot. 71:317-326.
6. Bryson, R. J., Paveley, N. D., Clark, W. S., Sylvester-Bradley, R., and Scott, R. K. 1997. Use of in-field measurements of green leaf area and incident radiation to estimate the effects of stripe rust epidemics on the yield of winter wheat. Eur. J. Agron. 7:53-62.

7. Clark, D. D. 1984. Tolerance of parasitic infection in plants. Pages 103108 in: Plant Diseases: Infection, Damage and Loss. R. K. S. Wood and G. J. Jellis, eds. Blackwell Scientific Publications, Oxford, UK.

8. Cox, W. J., and Otis, D. J. 1989. Growth and yield of winter wheat as influenced by chlormequat and ethephon. Agron. J. 81:264-270.

9. Foulkes, M. J., Spink, J. H., Scott, R. K., and Clare, R. W. 1998. Varietal typing trials and NIAB additional character assessments. Home-Grown Cereals Authority Final Project Report No. 174. Vol. 5. HGCA, London.

10. Foulkes, M. J., Sylvester-Bradley, R., Scott, R. K., Snape, J. W., and Worland, A. 2001. Maintaining wheat performance through improved resistance to drought. DEFRA Final Project Report. DEFRA, London.

11. Gale, M. D., and Youseffian, S. 1985. Dwarfing genes in wheat. Pages 135 in: Progress in Plant Breeding. G. E. Russell, ed. Butterworths, London.

12. Gaunt, R. E. 1981. Disease tolerance-an indicator of thresholds? Phytopathology 71:915-916.

13. Gaunt, R. E., and Wright, A. C. 1992. Disease-yield relationship in barley. II. Contribution of stored stem reserves to grain filling. Plant Pathol. 41:688-701.

14. Gay, A. P., Stokes, D. T., Weightman, R. M., and Sylvester-Bradley, R. 1998. How to run a reference crop. Home-Grown Cereals Authority Final Project Report No. 151. Vol. 2. HGCA, London.

15. Green, C. F. 1986. Modifications to the growth and development of cereals using chlorocholine chloride in the absence of lodging: a synopsis. Field Crops Res. 14:117-133.

16. Green, C. F., Dawkins, T. C. K., and Hunter, B. 1985. Influence of foliar applied chlormequat on radiation attenuation by winter barley canopies. J. Agric. Sci. 105:213-216.

17. Kenward, M. G., and Roger, J. H. 1997. The precision of fixed effects estimates from restricted maximum likelihood. Biometrics 53:983997.

18. Lovell, D. J., Parker, S. R., Hunter, T., Welham, S. J., and Nichols, A. R. 2004. Position of inoculum in the canopy affects the risk of Septoria tritici blotch epidemics in winter wheat. Plant Pathol. 53:11-21.

19. McKendry, A. L., and Henke, G. E. 1994. Tolerance to Septoria tritici blotch in soft red winter wheat. Cereal Res. Commun. 22:353-359.

20. Ministry of Agriculture, Fisheries and Food. 1997. Pesticide Usage Survey Report 141: Arable Farm Crops in Great Britain 1996. HMSO, London.

21. Monsi, M., and Saeki, T. 1953. Uber der lichtfactor in den pflanzengesellschaften und seine bedeutung fur die stoffproduktion. Jpn. J. Bot. 14:22-52.

22. Newton, A. C., and Thomas, W. T. B. 1994. Detection of tolerance of barley cultivars to infection by powdery mildew (Erysiphe graminis $\mathrm{f}$. $\mathrm{sp}$. hordei). Euphytica 75:179-187.

23. Newton, A. C., Thomas, W. T. B., Guy, D. C., and Gaunt, R. E. 1998. The interaction of fertilizer treatment with tolerance to powdery mildew in spring barley. Field Crops Res. 55:45-56.

24. Parker, S. R., Welham, S., Paveley, N. D., Foulkes, M. J., and Scott, R. K. 2004. Tolerance of Septoria leaf blotch in winter wheat. Plant Pathol. 53:1-10.

25. Paveley, N. D., Lockley, K. D., Sylvester-Bradley, R., and Thomas, J. 1997. Determinants of fungicide spray decisions in wheat. Pestic. Sci. 49:379-388

26. Roberts, J. J., Hendricks, L. T., and Patterson, F. L. 1984. Tolerance of leaf rust in susceptible wheat cultivars. Phytopathology 74:349-351.

27. Sabri, N., and Clarke, D. D. 1996. The relative tolerances of wild and cultivated oats to infection by Erysiphe graminis f. sp. avenae: 1. The effects of infection on vegetative growth and yield. Physiol. Mol. Plant Pathol. 49:405-421.

28. Sabri, N., Dominy, P. J., and Clarke, D. D. 1997. The relative tolerances of wild and cultivated oats to infection by Erysiphe graminis f. sp. avena: II. The effects of infection on photosynthesis and respiration. Physiol. Mol. Plant Pathol. 50:321-335.

29. Shearman, V. J. 2001. Changes in the yield limiting processes associated with the yield improvement of wheat. Ph.D. thesis, University of Nottingham, UK.

30. Shearman, V. J., Sylvester-Bradley, R., Scott, R. K., and Foulkes, M. J. 2005. Physiological processes associated with wheat yield progress in the UK. Crop Sci. 45:175-185.

31. Simons, M. D. 1972. Crown rust tolerance of Avena sativa-type oats derived from wild Avena sterilis. Phytopathology 62:1444-1446.

32. Snape, J. W., Law, C. N., Parker, B. B., and Worland, A. J. 1985. Genetical analysis of chromosome $5 \mathrm{a}$ of wheat and its influence on important agronomic characters. Theor. Appl. Genet. 71:518-526.

33. Tottman, D. R. 1987. The decimal code for the growth stages of cereals 
with illustrations. Ann. Appl. Biol. 110:441-454.

34. Waggoner, P. E., and Berger, R. D. 1987. Defoliation, disease and growth. Phytopathology 77:393-398.

35. Weyhrich, R. A., Carver, B. F., and Smith, E. L. 1994. Effects of awn suppression on grain yield and agronomic traits in hard red winter wheat. Crop Sci. 34:965-969.

36. Whelan, H. G., Gaunt, R. E., and Scott, W. R. 1997. The effect of leaf rust (Puccinia hordei) on yield response in barley (Hordeum vulgare L.) crops with different yield potentials. Plant Pathol. 46:397-406.

37. Yemm, E. W., and Willis, A. J. 1954. The estimation of carbohydrates in plant extracts by anthrone. Biochem. J. 57:5018-5014.

38. Ziv, O., and Eyal, Z. 1976. Evaluation of tolerance to Septoria leaf blotch in spring wheat. Phytopathology 66:485-488.

39. Zuckerman, E., Eshel, A., and Eyal, Z. 1997. Physiological aspects related to tolerance of spring wheat cultivars to Septoria tritici blotch. Phytopathology 87:60-65. 